\title{
QUANTOM - Non-destructive scanning of waste packages for material characterization
}

Dr. Andreas Havenith1, Dr. John Kettler ${ }^{1}$, Dr. Kai Krycki ${ }^{1}$, Martina Wangnick ${ }^{1}$, Dr. Bo Fu ${ }^{1}$, Dr. Martin Dürr1, Dr. Laurent Coquard², Günter Nordhardt², Julian Hummel2, Thomas Veltkamp², Sven Wegener ${ }^{2}$ Dr. Theo Köble ${ }^{3}$, Dr. Olaf Schumann ${ }^{3}$

\section{havenith@nuclear-training.de}

Aachen Institute for Nuclear Training $\mathrm{GmbH}$, Stolberg ${ }^{1}$

Framatome $\mathrm{GmbH}$, Erlangen ${ }^{2}$

Fraunhofer-Institut für Naturwissenschaftlich-Technische Trendanalysen, Euskirchen ${ }^{3}$

\section{Requirements regarding the characterization of waste packages}

For the safe intermediate storage and final disposal of radioactive waste, waste packages must comply with the waste acceptance requirements defined by national licensing and supervisory authorities. In Germany, the Konrad repository is planned to go into operation in 2027. Konrad is a geological repository for radioactive waste with negligible heat generation, which means low and intermediate level radioactive waste regarding an international classification. The federal company for radioactive waste disposal BGE (Bundesgesellschaft für Endlagerung) has established waste acceptance requirements for the repository Konrad and is responsible for the qualification of radioactive waste packages [1]. These requirements were developed on the basis of the results of a site-specific safety assessment. They include requirements on waste forms and waste containers, activity limitations as well as mass limitations to non-radioactive harmful substances. Requirements on documentation and delivery of waste packages are also implemented. The license for the construction and operation of the Konrad repository comprises limitations to nonradioactive harmful substances due to the water law [2]. According to that masses of non-radioactive harmful substances (waste package constituents) are limited. Waste packages to be disposed of must comply with those requirements, including a mandatory material description in correspondence to the water law. The chemical characterization of radioactive waste is done by material vectors. The raw materials, the waste matrix, backfill material and the container are described by the material vectors, which are stored in a central database hosted by BGE and made available online only for waste producers and their service providers.

Only qualified, in terms of quality assured waste packages, can be delivered and subsequently disposed of in the repository. To qualify waste packages, the producer is responsible to characterize every waste package regarding its radiological 
inventory and material composition. The characterization is checked by technical safety organizations and supervisory authorities. For the material description in principle, hazardous substances shall be quantified by traceability and quality controls performed during waste production and conditioning. However, for legacy waste poor or even no documentation with sufficient detail is available. Therefore, in most cases the documentation of legacy waste does not facilitate the retrospective characterization in order to fulfill the acceptance criteria. If the documentation is not sufficient, the characterization of waste packages by destructive or non-destructive analysis becomes mandatory. Until today, a review of legacy waste for the complete characterization usually involves an opening of the drums. Large quotas of legacy wastes are property of the public sector such as research institutions or waste from the early nuclear technology. In Germany, the opening for visual inspection or sampling leads to the waste being considered as new waste, which in contrast to legacy waste is subject to much more restrictive requirements. Furthermore, destructive testing methods demand repackaging of the waste, which consequently results in an increase of the volume. Therefore, non-destructive methods are to be preferred because the radiation exposure of the operating personnel and the waste volume is less. Based on this issue, there is an increasing need for a metrological characterization and plausibility check for the material composition of waste packages additional to the radiological characterization.

\section{State of the Art nondestructive assay (NDA) techniques}

Worldwide, segmented or integral gamma-scanning as well as active or passive neutron counting is used as the standard non-destructive measurement methods for the radiological characterization and quality assurance of radioactive waste packages [3]. These techniques determine the isotope-specific activities of radionuclides in waste packages, but they cannot detect non-radioactive yet hazardous substances within the waste packages. In addition to these methods, radiography or tomography of waste packages using a radioactive gamma-source or X-ray is particularly useful to investigate the contents of heterogenous waste drums. However, these imaging methods only show the attenuation of intense radiation and do not allow a direct identification of substances. Existing imaging procedures allow to distinguish between metal, organic compounds and concrete, but they are not able to distinguish between materials of similar densities, for example between cadmium and copper. Since the chemotoxic potentials of these elements differ a lot and cannot be determined by state-of-the-art non-destructive technology, there is a need for improvement in NDA techniques for waste characterization. 


\section{P\&DGNAA as the advanced methodology for scanning of nuclear drums}

In order to determine masses of non-radioactive substances in radioactive waste packages, especially drums, an innovative method based on Prompt and Delayed Gamma Neutron Activation Analysis (P\&DGNAA) is developed in Germany since 2007 [4-6]. P\&DGNAA is a standard method at research reactors for the analysis of small samples (mass range $\mathrm{mg}-\mathrm{g}$ ). As described in figure 1, PGNAA relies on the measurement of gamma radiation emitted promptly during the de-excitation of the compound nucleus as a consequence of neutron capture. These so-called prompt gamma-rays are emitted within less than $10^{-12} \mathrm{~s}$. Thus, their detection requires simultaneous gamma spectrum acquisition during neutron irradiation. DGNAA relies on the measurement of gamma rays that are emitted from the activation products. The timing of this delayed emission is characterized by the radioactive half-live of the activation product.

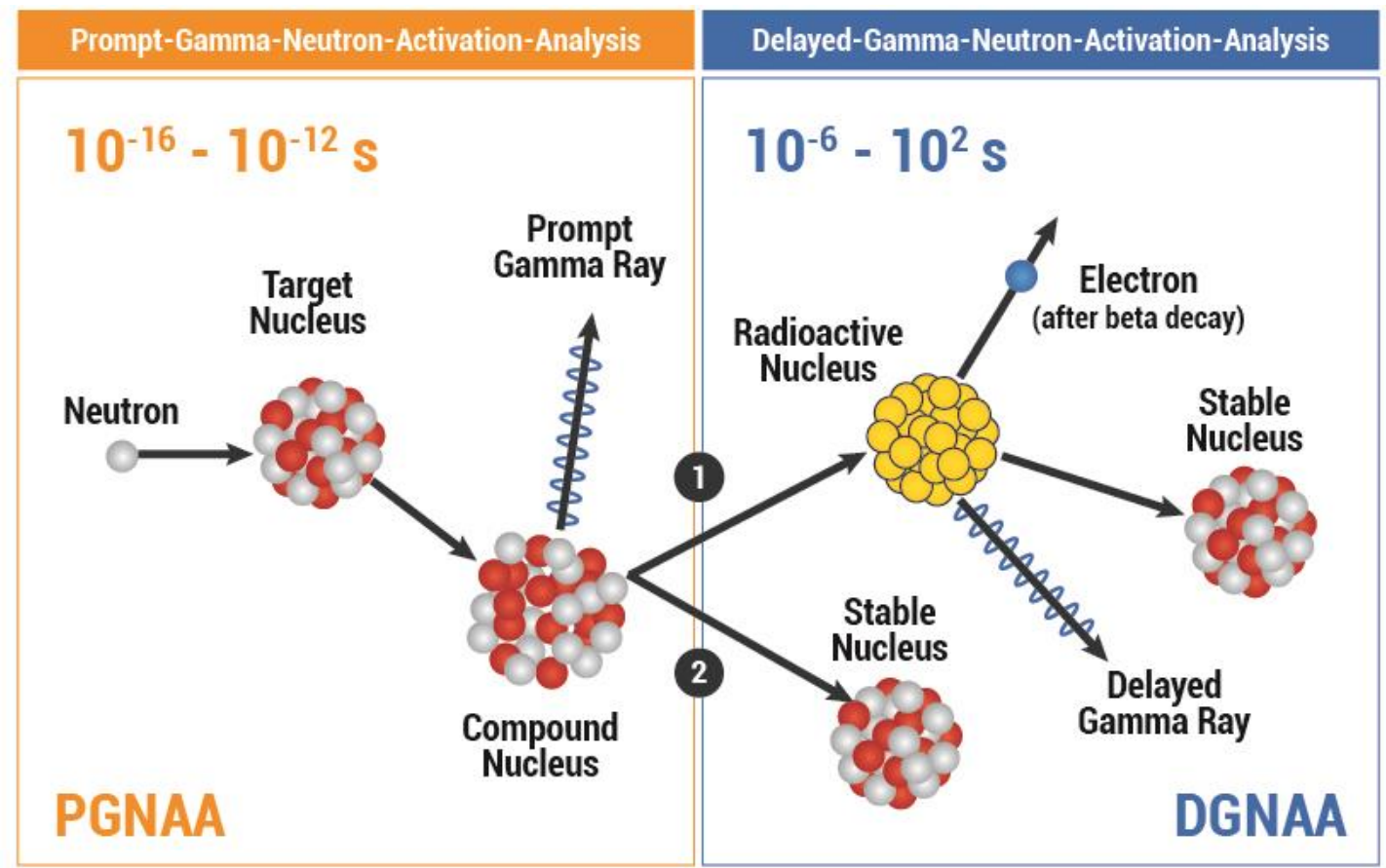

Figure 1: Physical basics of Prompt and Delayed Gamma Neutron Activation Analysis (P\&DGNAA).

The advantages of the P\&DGNAA for the scanning of waste packages are:

- non-destructive assay

- multi-element analysis with high sensitivity

- applicable for any waste form

- no advanced conditioning or preparation is necessary

- high energy neutrons as probe in combination with the induced high energy gamma rays allow high penetration capabilities and the representative investigation of the whole waste package. 


\section{The QUANTOM measurement device}

Framatome $\mathrm{GmbH}$, the Fraunhofer Institute for Technological Trend Analysis and the Aachen Institute for Nuclear Training $\mathrm{GmbH}$ are cooperating to develop an innovative drum inspection system for non-destructive analysis for the quality assurance of radioactive waste conditioned in 200-liter steel drums. The new nondestructive measurement device, called QUANTOM $^{\circledR}$ (QUantitative ANalysis of TOxical and non-toxical Materials), enables to scan 200-I-drums in order to identify and quantify materials contained in drums. The physical basis for the metrological analysis of QUANTOM $^{\circledR}$ is the P\&DGNAA. QUANTOM ${ }^{\circledR}$ supports the waste producers to in describing their waste products regarding material composition and can be used for a plausibility check. Based on the QUANTOM $^{\circledR}$ measurement results the waste producers can easily describe the constituents of the drum and select the right material vectors. Plausibility check means the verification of a material description carried out by material vectors based on QUANTOM $^{\circledR}$ measurements.

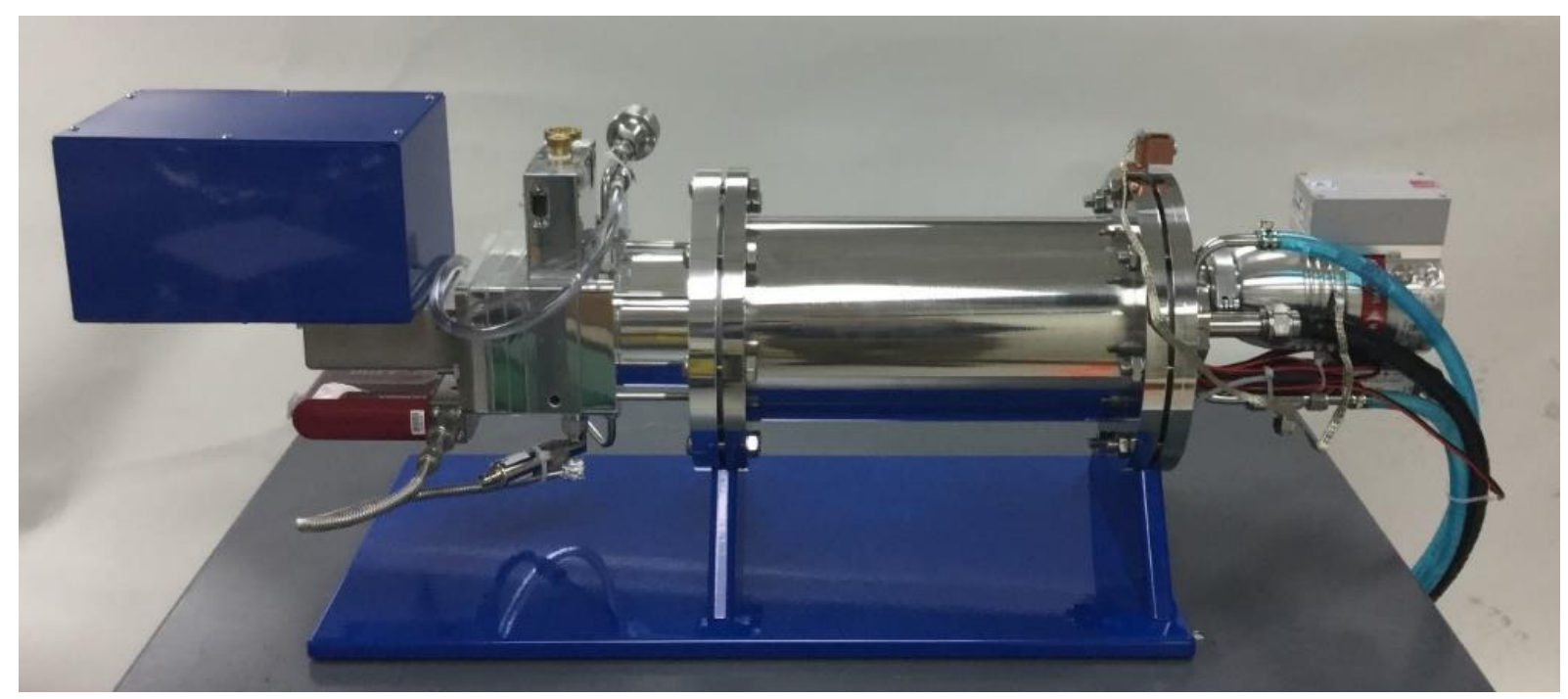

Figure 2: DD-Neutron generator by Adelphi Technology Inc.. These neutron generators operate by an ion beam supplied by a microwave plasma ion source and include an actively pumped vacuum system (Picture Source: with the kind permission of Adelphi Technology Inc.).

QUANTOM $^{\circledR}$ is developed for the non-destructive assay of $200-I$ waste drums with a maximum weight of $1 \mathrm{t}$. The irradiation of the drum takes place in an irradiation cell primarily made of high purity graphite, which acts as a neutron reflector and moderator. The drum is positioned in the middle of the irradiation cell on a lifting turntable to allow translation and rotation for collimated sectorial scans. A DeuteriumDeuterium (D-D) neutron generator produces neutrons with an energy of $2.5 \mathrm{MeV}$ and a total yield of $4 \times 10^{9}$ neutrons per second. It is positioned horizontally in a wall of the irradiation chamber. QUANTOM ${ }^{\circledR}$ uses a D-D neutron generator, which means that instead of D-T neutron generators no radioactive tritium is used. The electrically 
driven neutron generator accelerates deuterons with a high voltage power supply providing up to $150 \mathrm{kV}$. The neutron generator from the 109.X series of Adelphi Technology (shown in figure 2) has a compact design and is fully integrated in the measurement device. The neutron flux induces the measurement signal while the lower initial neutron energy of the D-D fusion reaction decreases the background signal. The generator can be operated in continuous or pulsed mode and is thus suitable for prompt as well as delayed gamma neutron activation.

The gamma rays induced by the thermal and epithermal neutron capture of the material in the drum are detected by two n-type High-Purity Germanium (HPGe) detectors with 60\% relative efficiency (see Figure 3). The HPGe detectors are electrically cooled, so that no liquid nitrogen is necessary for cooling. The HPGedetectors are placed in the walls of the irradiation chamber and are surrounded by a lead or bismuth collimator. Both the detector and collimator are shielded by composite plates out of highly enriched Li-6-carbonate and fluoroplastic to avoid thermal neutron capture within the germanium crystal.

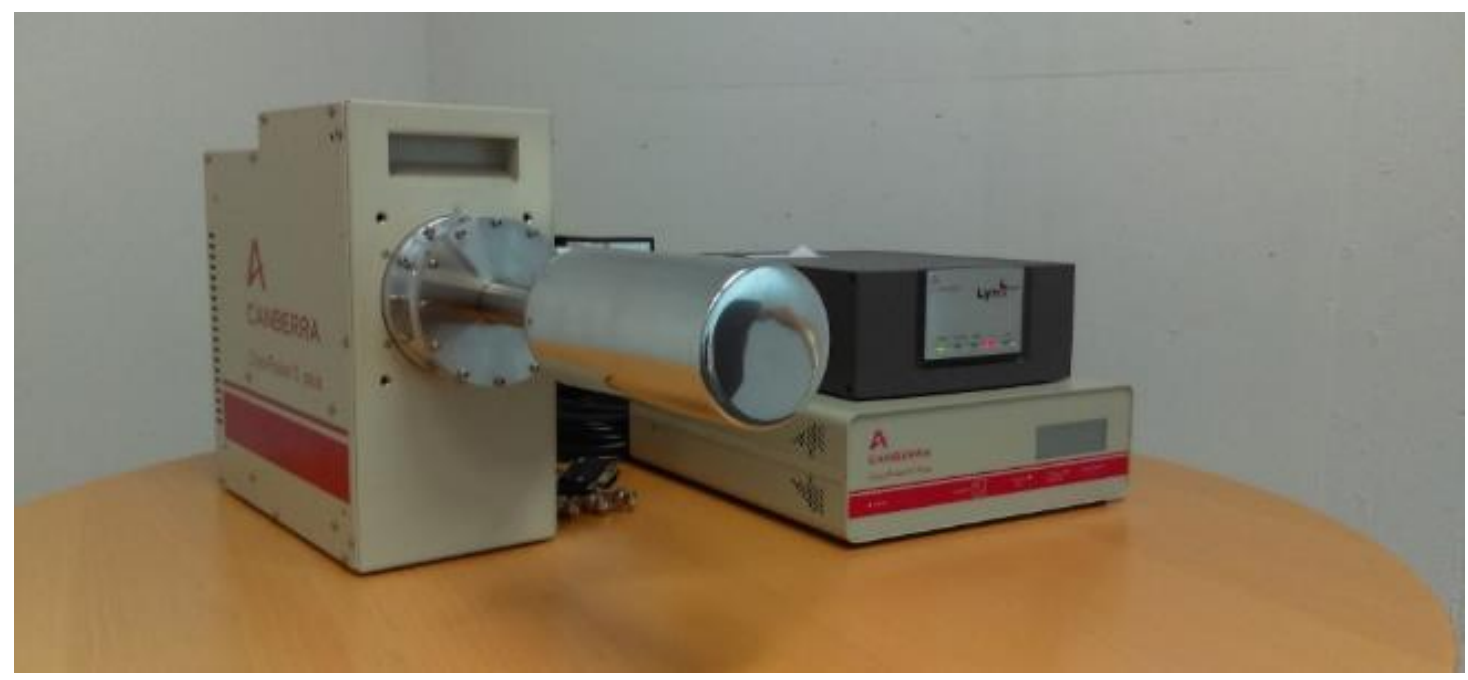

Figure 3: HPGe-Detectors by Mirion Technologies Canberra GmbH

The two HPGe detectors are positioned symmetrically allowing a simultaneous measurement of two segments of the drum. For the collimated measurements, the drum is segmented vertically into four segments (of approx. $22 \mathrm{~cm}$ height), and each segment is sub-divided into 12 angular sectors of $30^{\circ}$ (see figure 4). The angle between detector and neutron generator is $75^{\circ}$. The detectors are collimated to these segments and are positioned approximately $50 \mathrm{~cm}$ away from the surface of the drums, where the center of the detector crystal is in line with the center of the segment. Measurements are taken at fixed positions, i.e. the drum is not rotated continuously as in standard segmented gamma scanning. By rotating the drum in steps of $60^{\circ}$ to the next position, each segment can be completely measured with six measurements, and the whole drum with 24 measurements. The corresponding measuring scheme is illustrated in figure 4 by the color code of the sectors. 


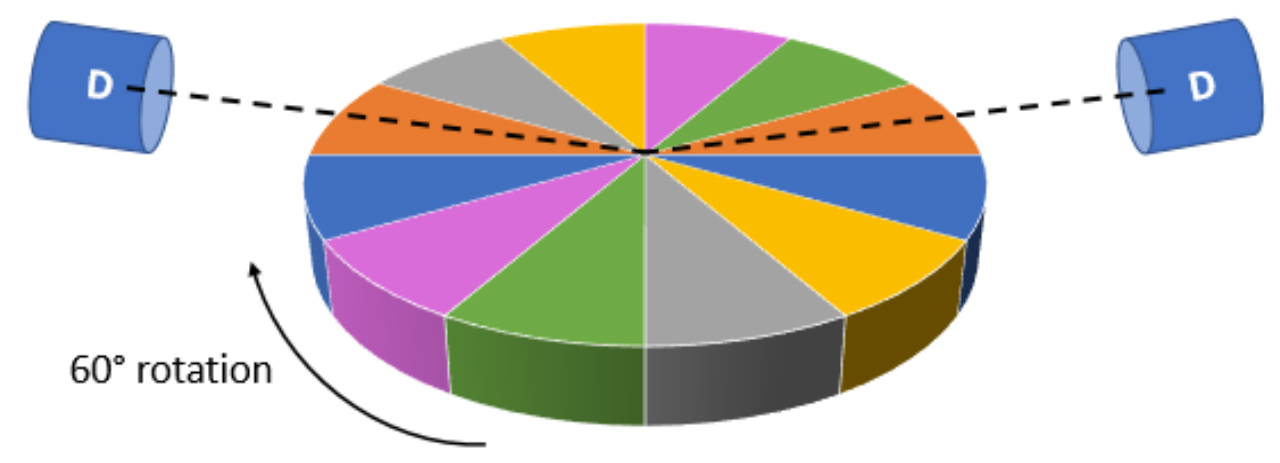

Figure 4: Measuring scheme for a single segment. Sectors with the same color are measured simultaneously. The next measurement position is reached by rotating 60 degrees.

The drum can be hydraulically moved in vertical direction to cover the four segments of the drum. In order to protect the graphite from mechanical damages by the moving drum, generator and measurement chamber are separated by a thin layer made of Polytetrafluoroethylene (PTFE, also known under the brand name Teflon ${ }^{\circledR}$ ). The turntable of the drum is also made of PTFE. This completely fluorinated plastic produces only a very low amount of measurement signal and is therefore advantageous for a low active underground measurement signal. Other structural materials are made of Zircaloy to reduce the active gamma underground signal.

The whole measurement device is surrounded by a shielding of borated polyethylene and steel lead sandwich panels. The shielded measurement device QUANTOM $^{\circledR}$ will be integrated in a 25' steel container in order to keep the sum of the gamma and neutron dose rate at the surface of the container below $10 \mu \mathrm{Sv} / \mathrm{h}$. If during operation the local dose rate at 0.1 meter from the walls of the container does not exceed the dose rate of $10 \mu \mathrm{Sv} / \mathrm{h}$ the measurement device only requires a notification according to $\S 17$ of the German Radiation Protection Act.

After experimental validation of $\mathrm{QUANTOM}^{\circledR}$, the measurement container can be transported to storage facilities or conditioning sites of waste producers to integrate the system directly in the waste management and characterization processes. The first prototype of QUANTOM $^{\circledR}$ will go into operation in 2019. In figure 5 the final design of the measurement device is shown together with the automatic drum loading system. QUANTOM ${ }^{\circledR}$ can be loaded with at least up to 10 drums, so only one loading per day is necessary. The system automatically transports one drum after the next into the correct position for measurement. The measuring time of one drum is 2 to 4 hours. Longer measuring times allow higher sensitivities in analysis. 


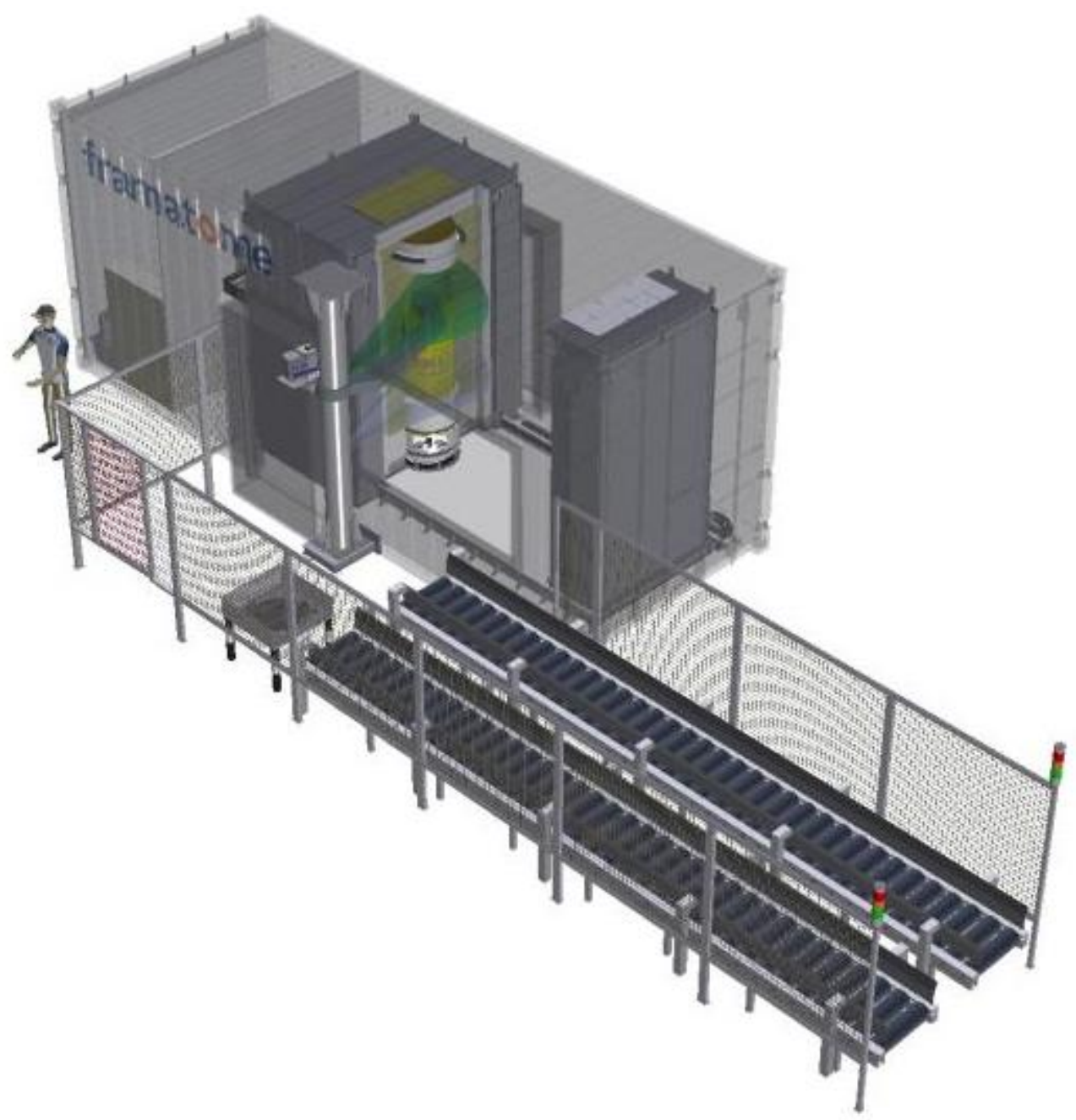

Figure 5: Design of the QUANTOM ${ }^{\circledR}$ measurement device integrated in a $25^{\prime}$-Container as well as the automatic drum loading system.

\section{Development of a gamma-spectroscopy software for mass quantification}

Based on the results from the analyzed P\&DGNAA spectra, it is possible to quantify the element fractions of the material in the drum. For the evaluation of gamma spectra, AiNT developed an in-house gamma spectroscopy software called PEAK ${ }^{\circledR}$. It is especially suited for P\&DGNAA. Therein, algorithms according to the state of science and technology are implemented and include current and verified nuclear physics databases of prompt and delayed gamma lines of the IAEA [7]. With these, it is possible to evaluate the peaks in the gamma spectra and assign them to the specific elements. The net peak area is determined by fitting a physical model [8] to the data (see figure 6). The PEAK ${ }^{\circledR}$ software enables to record the spectra and to analyze them for a complete identification of peaks and the calculation of corresponding net peak areas. 


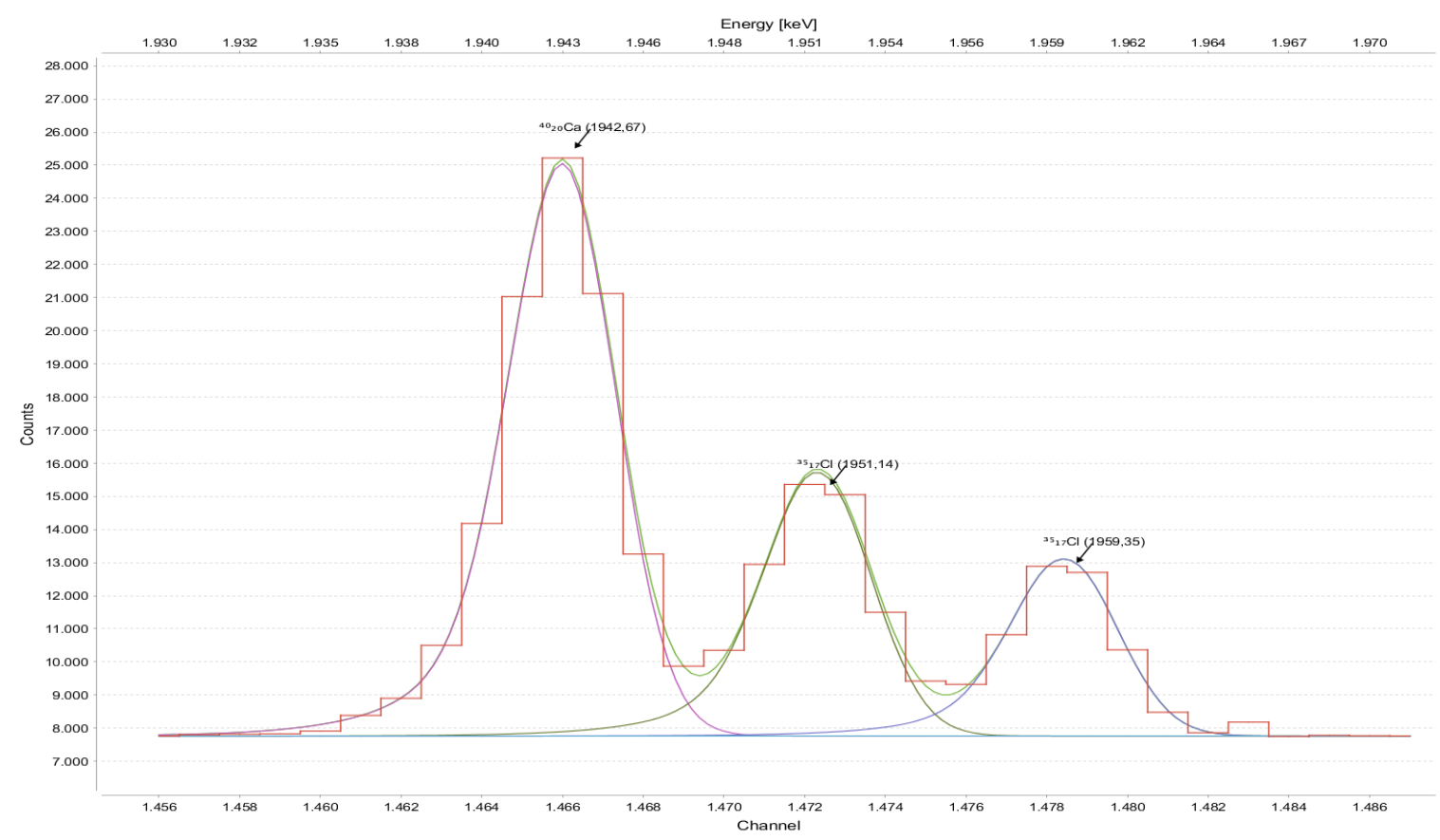

Figure 6: Region of Interest (ROI) of a real PGNAA gamma spectrum. This triplet in the energy range of $1.9 \mathrm{MeV}$ is caused by Calcium and two Chlorine peaks. In the software, the peaks are jointly fitted and can then be evaluated individually.

\section{Iterative approach for the determination of element masses}

In general, necessary measuring parameters such as photopeak efficiencies, partial cross sections for the emission of gammas and the spatially resolved neutron flux in the sectors cannot be calculated a priori. They are depending on the elemental composition of the sample, which has to be analyzed. Therefore, the determination of element mass fractions is an iterative process. To calculate accurate absolute mass fractions from the gamma signal, the spatial distribution of the neutron flux within the waste drum needs to be known. As the waste itself will alter the neutron distribution and flux, it is not possible to calculate the latter a priori from the gamma measurement. Hence the neutron flux has to be measured simultaneously with the gamma radiation. Based on the spatial resolved measured neutron flux outside of the drum and the determined mass fraction the neutron flux and distribution is calculated inside the drum by a deterministic transport code for neutrons assuming a diffusion approximation model. The neutron flux outside of the drum is measured online close to the surface of the drum by 32 Helium-3 proportional counters with a low gas pressure of 0.5 bar of He-3 and 1.0 bar of Argon.

An initial set of parameters, which will be calculated by Monte-Carlo simulations, is used to provide a first guess for the elemental composition. For the update of the parameters, an approach of correcting parameters based on the current composition 
is used. The photo peak efficiencies are mainly dependent on the material's density and can thus be corrected taking gamma self-shielding into account. A correction of the relative neutron spectrum can be achieved by calculating the spatially resolved neutron spectra and flux. From the relative neutron spectrum in the drum and tabulated cross section data the partial cross sections can be calculated. Updated parameters are then used to calculate a new elemental composition. This iterative process is repeated until the elemental composition stabilizes. This iterative analysis procedure and the QUANTOM $^{\circledR}$ measurement device is patented in Germany by AiNT with the European patent pending.

The current development status, additional info material and the sensitivities of the measuring system can be viewed at the following link:

https://www.nuclear-training.de/forschungsprojekte-details/quantom.html

\section{Service outlook by Framatome using QUANTOM}

With QUANTOM, Framatome will be able to offer an extensive service around the characterization of legacy waste for final disposal. This service includes:

- Plant and process engineering including pre-examinations

- Process qualification: registration of post-qualification, campaign planning and evaluation of procedures and feasibility

- Visual inspection

- Radiological characterization (by additional advanced drum measuring systems)

- Non-destructive material characterization: Monitoring, declaration and quantification of elements and substances with the aid of QUANTOM, clarification of the real waste package content

- Waste package documentation and control: compare existing documentation with regulatory requirements, complete/create documents based on national requirements

- Packaging and transportation planning

\section{Acknowledgements}

The joint project QUANTOM is being funded by the Federal Ministry of Education and Research under grant number 15S9406A / B / C. The responsibility for the content of this publication lies with the project partners. 


\section{References}

[1] Dr. Peter Brennecke, Requirements on Radioactive Waste for Disposal (Waste Acceptance Requirements of December 2014) - Konrad Repository -, $18^{\text {th }}$ December 2014.

[2] Niedersächsisches Umweltministerium: Planfeststellungsbeschluss für die Errichtung und den Betrieb des Bergwerkes Konrad in Salzgitter als Anlage zur Endlagerung fester oder verfestigter radioaktiver Abfälle mit vernachlässigbarer Wärmeentwicklung, Hannover, 22. Mai 2002.

[3] Management of low and intermediate level radioactive wastes with regards to their chemical toxicity; IAEA-TECDOC-1325; International Atomic Energy Agency IAEA; (2002)

[4] A. Havenith, Stoffliche Charakterisierung radioaktiver Abfallprodukte durch ein Multi-Element-Analyseverfahren basierend auf der instrumentellen NeutronenAktivierungs-Analyse - MEDINA -; Forschungszentrum Jülich, Energy \& Environment, Volume 248, ISBN 978-3-95806-033-2, (2015)

[5] J. Kettler: Prompt-Gamma-Neutronen-Aktivierung-Analyse zur zerstörungsfreien Charakterisierung radioaktiver Abfälle; Forschungszentrum Jülich, Energy \& Environment, Volume 82, ISBN 978-3-89336-665-1, (2010)

[6] E. Mauerhofer, A. Havenith, J. Kettler: Prompt gamma neutron activation analysis of a $200 \mathrm{~L}$ steel drum homogeneously filled with concrete, Journal of Radioanalytical and Nuclear Chemistry, (2015), http://link.springer.com/article/10.1007/s10967-016-4768-7

[7] Database of prompt gamma rays from slow neutron capture for elemental analysis, International Atomic Energy Agency, Vienna, ISBN 92-0-101306-X (2007)

[8] G. Philipps, K. Marlowe, Automatic analysis of gamma-ray spectra from germanium detectors, Nuclear Instruments and Methods, Vol. 137 (3), pp. 525-536 (1976) 